\title{
Is Glutamate Excreted by its Uptake System in Corynebacterium glutamicum? A Working Hypothesis
}

\author{
BY YVES CLEMENT, BERNARD ESCOFFIER, \\ MARIE CLAUDE TROMBE AND GILBERT LANÉELLE* \\ Centre de Recherche de Biochimie et Génétique Cellulaire du CNRS, Université Paul Sabatier \\ and Groupement Scientifique de Microbiologie, 118 route de Narbonne, F-31062 Toulouse cedex. \\ France
}

(Received 9 April 1984: revised 29 May 1984)

\begin{abstract}
A strain of Corynebacterium glutamicum used for industrial production of glutamate had uptake systems for $L$-glutamate and $L$-serine. These transport systems were inhibited by a protonophore and by an ionophore, indicating that they were driven by a proton-motive force. Cells grown in the presence of an acylated surfactant used in industry to trigger glutamate excretion are known to have a decreased phospholipid content and highly saturated lipids. These surfactant-treated cells were no longer able to accumulate glutamate, while the serine uptake remained undisturbed. As a working hypothesis, it is proposed that the surfactant-induced membrane modifications could specifically result in an uncoupling of the glutamate uptake system, which could consequently be used as a specific excretion system.
\end{abstract}

\section{INTRODUCTION}

Glutamate excretion by Brevibacterium or Corynebacterium strains is obtained in industrial processes by addition of an acylated surfactant containing saturated fatty acyl residues (Demain \& Birnbaum, 1968). This induces an increase in the saturated fatty acid content of the lipids (Huchenq, 1983; Takinami et al., 1968) and a large decrease in the phospholipid content of cells (Huchenq, 1983). These modifications of lipids are pertinent to excretion triggering but do not shed any light on the glutamate excretion mechanism.

The added surfactant does not stop growth but moderately inhibits it: thus the treated cells do not suffer from a generalized leakage of intracellular metabolites. This was confirmed in our tests with Corynebacterium glutamicum, since after surfactant addition the growth medium contained only trace amounts of amino acids, except glutamate and small amounts of alanine. In the absence of surfactant our strain excreted alanine, but no glutamate (unpublished result). This indicated that alanine was exported by a specific system; however it seemed unlikely that a cell could have a device synthesized only to expel one amino acid. Most bacterial species have specific uptake systems to accumulate amino acids (Anraku, 1980). It can be imagined that the alanine excretion in $C$. glutamicum occurs through a system that retains its specificity but has lost the ability to accumulate alanine, so it works only in the direction imposed by the alanine concentration gradient, as in the case of some transport systems in eukaryotic cells (Christensen, 1969; Guidotti et al., 1978). This could also be postulated for glutamate excretion by $C$. glutamicum during growth in the presence of the surfactant.

Here we show that the glutamate-excreting bacterium $C$. glutamicum has a glutamate accumulation system, and some of its properties are presented. They differ in some respects from those of glutamate transport in Brevibacterium flatum (Mori \& Shiio. 1983). Based on the results obtained, a model for glutamate excretion mechanism is described.

Abbreriotion: CCCP. carbonyl cyanide m-chlorophenylhydrazone. 


\section{METHODS}

Chemicals. ${ }^{14} \mathrm{C}$-labelled $\mathrm{L}$-glutamate and L-serine, and ${ }^{3} \mathrm{H}_{2} \mathrm{O}$, were purchased from the Commissariat à l'Energie Atomique (CEN de Saclay, France), and inulin $-{ }^{1+} \mathrm{C}$ ) CCCP and chloramphenicol were purchased from Sigma. Polyoxyethyleneglycol stearate (Simulsol M49). subsequently called acylated surfactant, was obtained from Seppic-Montanoir (Paris, France).

Bacterial growth. The strain of $C$. glutamicum used was obtained from a glutamate-producing company. Cells were grown in Erlenmeyer flasks on a rotary shaker, at $30^{\circ} \mathrm{C}$, final $\mathrm{pH} 8$, in the growth medium specified below. The basal salt medium contained (per litre): $3 \mathrm{~g}\left(\mathrm{NH}_{4}\right)_{2} \mathrm{SO}_{4}, l_{\mathrm{g}} \mathrm{KH}_{2} \mathrm{PO}_{4}, 3_{\mathrm{g} \mathrm{K}} \mathrm{HPO}_{4}, 0.1 \mathrm{~g}-\mathrm{MgSO}_{4} .7 \mathrm{H}_{2} \mathrm{O}$, $1 \mathrm{mg} \mathrm{CaCl}_{2}, 8.5 \mathrm{mg} \mathrm{ZnSO}_{4} .7 \mathrm{H}_{2} \mathrm{O}, 1.3 \mathrm{mg} \mathrm{FeCl}_{3}, 0.4 \mathrm{mg} \mathrm{CuSO}_{4}, 90 \mathrm{mg} \mathrm{Na}_{2} \mathrm{~B}_{4} \mathrm{O}_{7} .7 \mathrm{H}_{2} \mathrm{O}, 72 \mathrm{mg} \mathrm{MnCl}_{2}, 4 \mathrm{H}_{2} \mathrm{O}$ and $37 \mathrm{mg}\left(\mathrm{NH}_{4}\right)_{2} \mathrm{MoO}_{4}$. The growth medium was obtained by adding (per litre of basal medium) $30 \mu \mathrm{g}$ biotin, $100 \mu \mathrm{g}$ thiamin, $4.5 \mathrm{~g}$ urea and $20 \mathrm{~g}$ sucrose.

The acylated surfactant was added at mid-exponential growth phase (0.5\% final concn).

Cell tolume. This was determined by using ${ }^{3} \mathrm{H}_{2} \mathrm{O}$ and inulin- $\left.-{ }^{14} \mathrm{C}\right)$ carboxylate according to the procedure of Stock et al. (1977) with the following modifications to avoid errors due to the turbidity introduced by bacterial cells into the scintillation counting mixtures. This procedure gave us reproducible results. Cells were washed with $0 \cdot 1 \mathrm{M}$ sodium phosphate buffer $\mathrm{pH} 7.8$, and thereafter maintained near $4^{\circ} \mathrm{C}$. To $\mathrm{I} \mathrm{ml} \mathrm{of} \mathrm{cell} \mathrm{suspension} \mathrm{containing} 2$ $4 \mathrm{mg}$ cell dry weight were successively added non-labelled inulin $\left(0.9 \mathrm{~mm}\right.$ final concn), inulin- $\left.{ }^{1+} \mathrm{C}\right)$ carboxylic acid and ${ }^{3} \mathrm{H}_{2} \mathrm{O}$ with a total radioactivity (c.p.m.) at least ten times that of the ${ }^{14} \mathrm{C}$-labelled compound $\left(5 \mu \mathrm{Ci}{ }^{3} \mathrm{H}\right.$ and $0.05 \mu \mathrm{Ci}{ }^{1+} \mathrm{C}$ were used in our assays; $1 \mu \mathrm{Ci}=37 \mathrm{kBq}$ ). Cells were immediately sedimented by centrifugation at $6000 \mathrm{~g}$ for $10 \mathrm{~min}$, and the radioactivity of $100 \mu \mathrm{l}$ of the supernatant was counted. The cell pellet was separated from the supernatant, and $500 \mu \mathrm{l}$ buffer was added to the cells. The cells were sedimented again and $400 \mu \mathrm{l}$ of the supernatant used for counting.

Counting of the first supernatant gives $\mathrm{H}_{S}\left({ }^{3} \mathrm{H}\right.$ c.p.m.) and $\mathrm{C}_{S}\left({ }^{1+} \mathrm{C}\right.$ c.p.m.); counting of $400 \mu \mathrm{l}$ of the second supernatant gives $H_{p}$ and $C_{p} . V_{p}$, the total volume of the first pellet, i.e. the volume accesible to ${ }^{3} H_{2} O$, is given (in HI) by:

$$
V_{p}=\frac{\left(500+V_{p}\right)}{400} \times \frac{H_{p}}{H_{s} / 100}=\frac{500 H_{p}}{4 H_{s}-H_{p}}
$$

$V_{n}$, the free water volume in first pellet, i.e. the volume accessible to inulin, is given (in $\mu l$ ) by:

$$
v_{w}=\frac{\left(500+V_{p}\right)}{400} \times \frac{C_{p}}{C_{s} / 100}=\frac{\left(500+V_{p}\right)}{4} \times \frac{C_{p}}{C_{s}}
$$

$V_{1}$, the intracellular volume, i.e. the volume non-accessible to inulin, in $\mu l(m g \text { dry } w t)^{-1}$, is given by : $V_{1}=$ $\left(V_{p}-V_{W}\right)$ /pellet dry weight. The intracellular volume was determined to be $1.76 \pm 0.20 \mu l(m g \text { dry wt })^{-1}$.

Amino acid uptake. The inorganic medium used for uptake experiments, subsequently called "basal uptake medium: was the basal salt medium defined above, but minus $\left(\mathrm{NH}_{4}\right)_{2} \mathrm{SO}_{4}$.

Cells grown to an OD $_{650}$ of about 7 (measured with a Zeiss PMQ III spectrophotometer) were collected by centrifugation at $6000 \mathrm{~g}$ for $5 \mathrm{~min}$ and washed three times with basal uptake medium ( $1 \mathrm{ml}$ of cell suspension with on $\mathrm{OD}_{650}$ of I corresponded to $0.2 \mathrm{mg}$ cell dry weight). Stocks of cells $\left(\mathrm{OD}_{650}=10\right)$ were kept in the same medium in ice. A $0.1 \mathrm{ml}$ sample of cell suspension was added to $0.9 \mathrm{ml}$ of the basal uptake medium containing $0.05 \mathrm{~g}$ sucrose $1^{-1}$ plus $0.1 \mathrm{mg}$ chloramphenicol $\mathrm{ml}^{-1}$, and incubated at room temperature for $\mathbf{3 0} \mathrm{min}$ with vortex agitation. Uptake was initiated by adding a ${ }^{1+} \mathrm{C}$-labelled amino acid (about $1 \mu \mathrm{Ci}$ per assay, final concn 4-6 $\mu \mathrm{M}$ ). Samples of $100 \mu \mathrm{l}$ were filtered under gentle suction on Whatman GF/B glass fibre filters. The filters were washed three times with $2 \mathrm{ml} 0.1 \mathrm{M}$-sodium phosphate buffer pH 7.8, dried and counted. The first sample was taken immediately after addition of the amino acid and used as a blank value.

The accumulation factor of amino acids within cells were calculated as follows. If $C_{1}$ and $C_{e}$ are the intracellular and extracellular amino acid concentrations respectively, $V_{e}$ is the extracellular volume in the filtered sample, and $R_{1}$ and $R_{t}$ are the intracellular and total radioactivity (in c.p.m.) of the filtered sample respectively. then the accumulation factor $C_{1} / C_{e}=\left(V_{e} / V_{1}\right) \times R_{1} /\left(R_{1}-R_{1}\right)$. In our experiments we estimated that $V_{e} / V_{1}=3000$.

Radioactivity counting. The scintillation mixture for wet samples contained $4 \mathrm{~g}$ PPO and $0.1 \mathrm{~g}$ POPOP in $333 \mathrm{ml}$ Triton X-100 plus $667 \mathrm{ml}$ toluene. The scintillation mixture for dry samples contained $5 \mathrm{~g}$ PPO and $0 \cdot 1 \mathrm{~g}$ POPOP in 1 litre toluene. The radioactivity was then measured in an Intertechnique liquid scintillation spectrometer.

\section{RESULTS AND DISCUSSION}

\section{Evidence for a glutamate-specific uptake system}

As it is known that some glutamate transport systems are stimulated by $\mathrm{Na}^{+}$, in a preliminary assay glutamate uptake by $C$. glutamicum was tested in either a $\mathrm{Na}^{+}$or a $\mathrm{K}^{+}$medium (Table 1 ). The $\mathrm{Na}^{+}$stimulation noted in Escherichia coli (Frank \& Hopkins, 1969) was not observed in our 
Table 1. Influence of assay medium composition on L-glutamate accumulation

\author{
Assay medium* \\ 40 mu-sodium phosphate \\ 40 mM-potassium phosphate \\ 20 mu-sodium phosphate + \\ $20 \mathrm{~mm}$-potassium phosphate \\ Basal salt medium
}

Accumulation factort
231
521
528
882

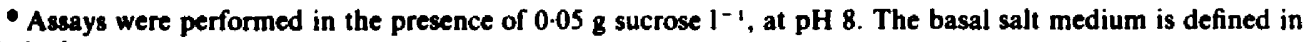
Methods.

$\uparrow$ Determined 20 min after addition of the $\mathrm{L}-{ }^{14} \mathrm{Clglutamate}$, as indicated in Methods.
}

strain of $C$.glutamicum. The best medium to test uptake seemed to be the basal salt medium plus $0.05 \mathrm{~g}$ sucrose $^{-1}$. In the experiments described below the basal salt medium was used without any nitrogen source, in order to limit amino acid synthesis during transport assays. At the plateau level (20-25 min accumulation) glutamate was concentrated by the cells $10^{3}-$ to $2 \times 10^{3}$. fold, depending on the culture.

The specificity of the glutamate uptake system was tested by measuring $\left[{ }^{1+} \mathrm{C}\right] \mathrm{glutamate}$ uptake in the presence of a 100 -fold excess of non-labelled amino acids for $30 \mathrm{~min}$. The system was highly specific for L-glutamate and L-aspartate since only these amino acids were strong competitors (i.e. decreasing uptake to $1-3 \%$ of the uninhibited value). L-Pyroglutamate, $N$ methyl-L-glutamate and D-glutamate had no effect, and all other naturally occurring amino acids tested gave inhibition percentages too small to be significant (4-30\%) under our experimental conditions, with the possible exception of $\mathrm{L}$-glutamine $(35 \%$ inhibition). The glutamate uptake system described in B. flarum (Mori \& Shiio, 1983) differs in its specificity in that L-glutamine does not inhibit it, while D-glutamate seems to be slightly inhibitory.

\section{Energy source of L-glutamate transport}

We looked for a proton-motive force dependence of the glutamate uptake by using uncouplers (for data on their action see Ahmed \& Booth, 1983; Terada, 1981). The protonophore CCCP (used at pH 7) is known to lower the proton-motive force efficiently. CCCP abolished transport when added before glutamate and led to the release of most of the glutamate accumulated over $10 \mathrm{~min}$ under the usual uptake conditions (Fig. $1 a$ ).

To determine whether the two components of the proton-motive force participate in driving

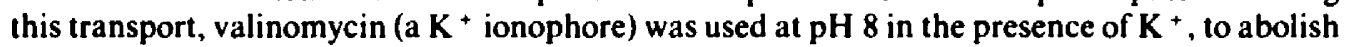
the transmembrane potential (Fig. $\mid b$ ). Under these conditions, valinomycin had the same effect as CCCP. Nigericin is a $\mathrm{H}^{+} / \mathrm{K}^{+}$-exchanging ionophore; used at $\mathrm{pH} 6$, it abolishes the transmembrane proton gradient, without changing the transmembrane potential. As shown in Fig. $1(c)$, nigericin abolished glutamate uptake. These results indicate that both the transmembrane potential and the proton gradient are used to accumulate glutamate. Valinomycin is not an inhibitor of the B. flarum system (Mori \& Shiio, 1983).

\section{Serine transport}

The transport of this amino acid was briefly studied in order to compare the effects of the conditions inducing glutamate excretion on the uptake of an amino acid not excreted. Since there was no competition between these two amino acids it can be concluded that serine and glutamate do not share a common transport system.

It is likely that serine was also accumulated by using a proton-motive force, since its uptake was inhibited by CCCP and valinomycin (Fig. 2). At the tested $\mathrm{pH}$ values $(6 \cdot 5,7,7 \cdot 5,8)$ there was more inhibition by valinomycin than by CCCP, indicating that serine uptake is strongly potential dependent.

\section{Effects of a surfactant on glutamate uptake}

It appears that the addition of uncouplers during an uptake experiment resulted in the release of at least half of the accumulated glutamate (Fig. 1). In the following assays it was tested 


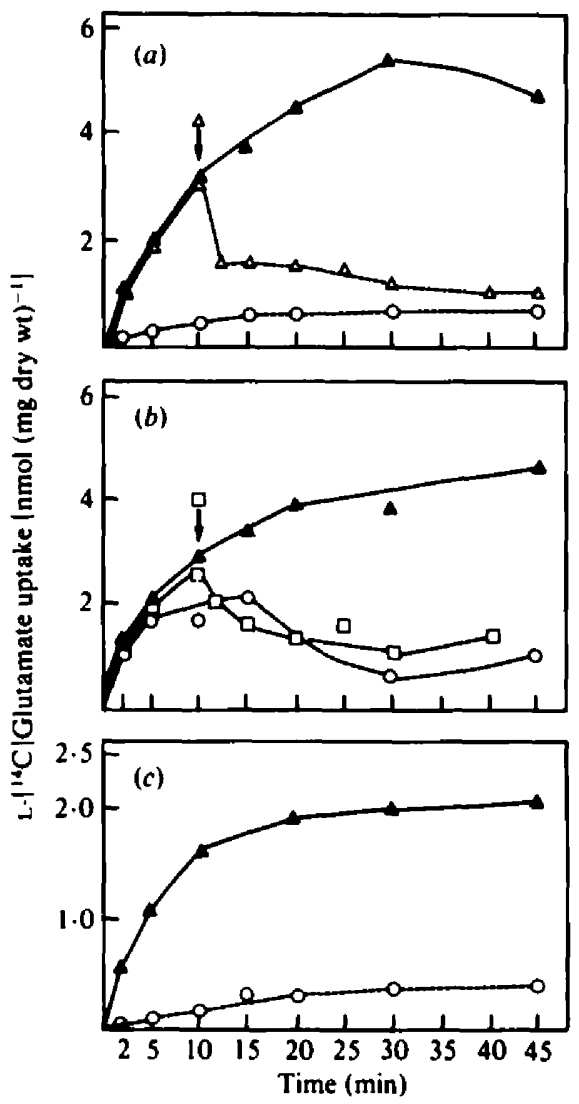

Fig. I. Effect of ionophores on L-glutamate uptake by $C$. glutamicum. Results are expressed in nmol $\mathrm{L}-f^{14} \mathrm{Clg}$ lutamate retained per $\mathrm{mg}$ cell dry weight. (a) Effect of CCCP. CCCP $\left(10^{-5} \mathrm{u}\right.$ final concn) was added either at zero time $(O)$, or after 10 min uninhibited uptake as indicated by the arrow $(\triangle)$. $\Delta$. Uninhibited control. The assays were performed at $\mathrm{pH} \mathrm{7.0.(b)}$ Effect of valinomycin. Valinomycin ( $10^{-5} \mathrm{M}$ final concn) was added either at zero time $(O)$, or after $10 \mathrm{~min}$ uninhibited uptake, as indicated by the arrow ( $\square$ ). $\triangle$. Uninhibited control. The assays were performed at pH 8.0. (c) Effect of nigericin. Nigericin $\left(10^{-7} \mathrm{M}\right.$ final concn) was added at zero time $(\mathrm{O}) . \Delta$. Uninhibited control. The assays were performed at pH 6.0.

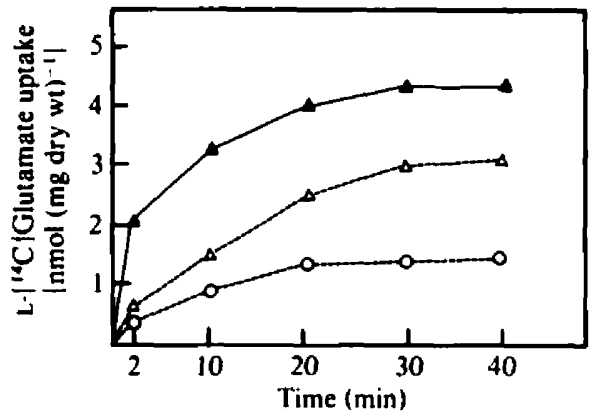

Fig. 2. Effect of CCCP and valinomycin on L-serine uptake by $C$. glutamicum. Conditions were as in Fig. 1 and assays performed at pH 8.0. O. Valinomycin; $\triangle, C C C P$ : $\triangle$, uninhibited control. 


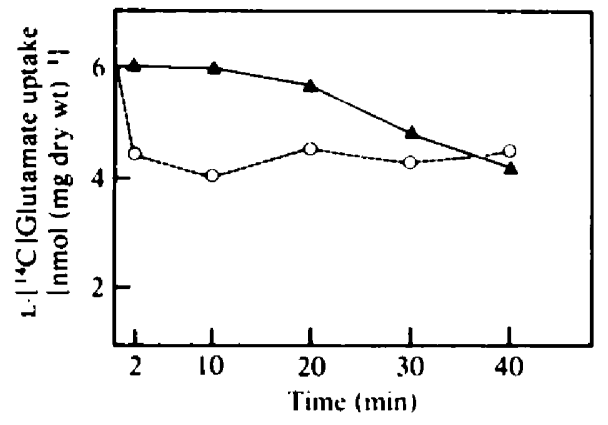

Fig. 3

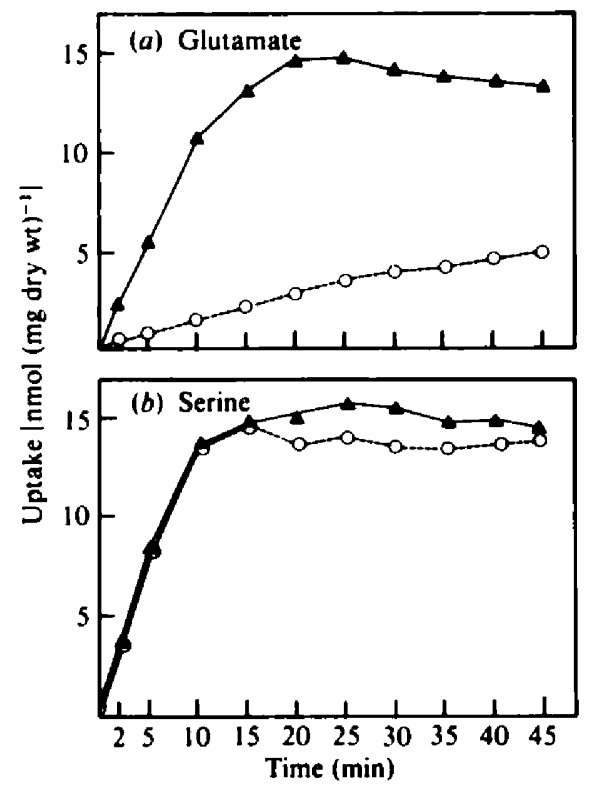

Fig. 4

Fig. 3. Effect of the acylated surfactant Simulsol M49 on L-glutamate content of cells. Cells were loaded with $\mathrm{L}-f^{1+} \mathrm{Clglutamate}$ during a $30 \mathrm{~min}$ uptake experiment, then at zero time the surfactant was added $(0.5 \%$ final concn), and $0.1 \mathrm{ml}$ samples were filtered and counted. $O$. Assay with surfactant: $\Delta$. control assay without surfactant.

Fig. 4. Effect on L-glutamate and L-serine uptake of the presence of the surfactant Simulsol M49 during growth. Cells were grown for $1 \mathrm{~h}$ in the presence of the surfactant $(0.5 \%$ final concn), then assayed for $\mathrm{L}$ glutamate $(a)$ and L-serine (b) uptake. $O$. Uptake by treated cells; $\boldsymbol{\Delta}$, uptake by control cells.

whether an acylated surfactant had an uncoupling effect on glutamate uptake. After the addition of the surfactant there was only a small release of the glutamate accumulated at the plateau, even $20 \mathrm{~min}$ after this addition (Fig. 3). It can be concluded that the surfactant molecule by itself could not promote glutamate excretion in the absence of growth, for instance by acting like an uncoupler.

Glutamate and serine uptake were tested in cells grown for some time in the presence of the acylated surfactant, since it is known that in the industrial process the specific rate of glutamate excretion increases during the hours following the surfactant addition, in parallel with the lipid modifications (A. Huchenq and others, unpublished results). Cells grown in the presence of the surfactant were strongly inhibited in their uptake of glutamate, while the transport of serine was not affected (Fig. 4). It can be concluded that the surfactant-induced alteration of the membrane did not result in a generalized leakiness of the membrane nor in a general uncoupling of the potential-driven transport systems; rather there were effects on specific membrane systems, particularly on the glutamate uptake system, which seemed to become uncoupled.

\section{Conclusion}

The strain of $C$. glutamicum used in the present study had an active transport of glutamate, the energy source of which was the proton-motive force. This specific uptake system could excrete glutamate, once the cells were uncoupled by a protonophore. As the surfactant used to induce glutamate excretion severely decreased glutamate uptake, it can be proposed that the surfactantinduced modification of the cell membrane resulted in a severe uncoupling of the glutamate uptake system during growth. This effect appeared to be a specific property of the glutamate transport system in the glutamate-producing strain, since active serine uptake was not uncoupled. 
A model for glutamate excretion could be as follows: the acylated surfactant added to the culture is adsorbed on the cell wall and cytoplasmic membrane (Huchenq, 1983); it induces an increase of the saturated fatty acid content of lipids and a degradation of nearly half of the membrane lipids (Huchenq, 1983). These alterations lead to a severe change of the glutamate transport system environment and to its uncoupling. As a consequence, the glutamate transporter becomes able to export glutamate and this continuous leak derepresses the glutamate biosynthesis.

The authors are grateful to François Ferré, a graduate student, for performing preliminary experiments and to Michèle Welby for her skilful technical assistance.

\section{REFERENCES}

AHMED, S. \& Booth, R. I. (1983). The use of valinomycin, nigericin and trichlorocarbanilide in control of the proton motive force in Escherichia coli. Biochemical Journal 212, 105-112.

ANRAKU, Y. (1980). Transport and utilisation of amino acids in bacteria. In Microorganisms and Nitrogen Sources, pp. 10-33. Edited by J. W. Payne. New York: Wiley.

Christensen, H. N. (1969). Some special kinetic problems of transport. Adrances in Enzymology 32. I-20.

Demain, A. L. \& Birbaum, M. J. (1968). Alteration of permeability for the release of metabolites from microbial cells. Current Topics in Microbiology 46, 125.

Frank, L. \& Hopkins, I. (1969). Sodium-stimulated transport of glutamate in Escherichia coli. Journal of Bacteriology 100, 329-336.

GUtDotTI, G. G., Borghetti, A. F. \& Gazzola, G. C. (1978). The regulation of amino acid transport in animal cells. Biochimica et biophy'sica acta 513, 329 336.
HUCHENQ, A. (1983). Excrétion du glutamate par Corynebacterium glutamicum: réexamen des altèrations membranaires déclenchant l'excrétion. Thèse de doctorat de 3ème cycle (Microbiologie), Université P. Sabatier, Toulouse.

MORI, M. \& SHIIO, I. (1983). Glutamate transport and production in Bretibacterium flacum. Agricultural and Biological Chemistry 47, 983-990.

Stock, J. B., Rauch, B. \& Roseman, S. (1977). Periplasmic space in Salmonella typhimurium and Escherichia coli. Journal of Biological Chemistry 252. 7850-7861.

Takinami, K., Yoshit, H., Yamada, Y., Okada, H. H. \& Kinoshita, K. (1968). Control of L-glutamic acid fermentation by biotin and fatty acids. Amino Acid and Nucleic Acid 18, 120-160.

TeradA, H. (1981). The interaction of highly active uncouplers with mitochondria. Biochimica et biophysica acta 639, 225-242. 